\title{
Subacromial impingement syndrome: management challenges
}

This article was published in the following Dove Press journal:

Orthopedic Research and Reviews

\section{Paolo Consigliere' \\ Omar Haddo 2 \\ Ofer Levy ${ }^{1,3}$ \\ Giuseppe Sforza'}

'The Reading Shoulder Unit, Berkshire Independent Hospital Coley Park, Swallows Croft, Reading, Berkshire, UK; ${ }^{2}$ The Whittington Hospital NHS FT, London, UK; ${ }^{3}$ The Reading Shoulder Unit, Royal Berkshire NHS Foundation Trust, Reading, Berkshire, UK
Correspondence: Paolo Consigliere The Reading Shoulder Unit, Berkshire Independent Hospital Coley Park, Swallows Croft, Wensley Rd, Reading, Berkshire RGI 6UZ, UK

Tel +44798 6252865

Email paoloconsigliere@gmail.com

\begin{abstract}
The painful shoulder is the most common condition seen in specialist shoulder clinics. It is often associated with lack of range of motion and reduced shoulder function. Lack of sleep and difficulties in performing basic daily life activities are common findings. Subacromial Impingement Syndrome (SAIS) has been considered as the most common cause of shoulder pain since it was described in 1852. Charles Neer, in 1972, described the presence of a "proliferative spur and ridge" on the undersurface of the acromion, which needs to be removed to improve the symptoms (acromioplasty). Neer's "impingement" hegemony was undisputed for at least 30 years. A more extensive knowledge of the pathogenesis of SAIS, however, has led authors to challenge the role of "impingement" in the shoulder pain and the role of surgical intervention. The aim of this review was to understand if there is still a role for surgical decompression in patients with SAIS. A literature review was performed in PubMed, PEDro, Embase, and the Cochrane Central Register of Controlled Trials using impingement, subacromial space, rotator cuff tears, tendinopathy, and tendinitis as key words. Randomized clinical trials (RCTs) with long-term follow-up comparing surgical intervention and conservative treatments in SAIS were preferred; however, prospective articles studying the outcome of surgical decompression and physiotherapy were also included. The majority of the studies showed no difference in the outcome between patients randomized to surgical decompression or conservative management. However, some studies reported better results after surgery, especially in the long term. Interpretation of the results is very difficult as most of the studies are of poor quality and have short follow-up. In our opinion, the type of subacromial lesion needs to be considered; this may offer an explanation to the difference in severity of symptoms and to the varying degrees of response to certain treatments, including surgery. Further studies are mandatory to better understand the role of surgery in SAIS.
\end{abstract}

Keywords: impingement, bursitis, supraspinatus tendon, rotator cuff, rotator cuff tears, tendinopathy, tendinitis

\section{Introduction}

Subacromial Impingement Syndrome (SAIS) is the commonest disorder of the shoulder, accounting for $44 \%-65 \%$ of all complaints of shoulder pain. ${ }^{1}$

In a Dutch study, the incidence of new cases of rotator cuff tendonitis in general practice was found to be around 3.2-4.2 per 1,000 person-years, and the corresponding incidence of shoulder pain (all causes) was 11.2 per 1,000 person-years. ${ }^{2}$ In the United Kingdom, the estimated percentage of people seeking treatment for shoulder pain in the general practice setting is between $20 \%$ and $50 \%$ in a life time. ${ }^{3}$ Among these patients, one in four sought medical care for SAIS. ${ }^{4}$ Its prevalence is especially high 
in repetitive overhead sports such as swimming, volleyball, handball, and manual jobs requiring prolonged overhead position of the arm (builders, electricians, hairdressers, etc).

Shoulder impingement results from an "inflammation and degeneration of the anatomical structures in the region of the subacromial space". 5 The subacromial space is defined by the humeral head inferiorly, the anterior edge and under surface of the anterior third of the acromion, coracoacromial ligament, and the acromioclavicular joint superiorly. The height of space between acromion and humeral head ranges from 1.0 to $1.5 \mathrm{~cm}$ as seen on radiographs (anteroposterior view). ${ }^{6}$ As the arm is abducted or rotated, the subacromial space width changes and the humerus gets closer to the anteroinferior edge of the acromion. This is true especially at $90^{\circ}$ of abduction and $45^{\circ}$ internal rotation of the shoulder. ${ }^{7}$

If the fine balance that regulates the shoulder kinematics is compromised, the humeral head migrates superiorly and the bursa protecting the rotator cuff, as well as the cuff itself becomes increasingly compressed.

Neer described the presence of a proliferative "spur" and ridge on the undersurface of the acromion (anterolaterally), which was recognized as the cause of the "impingement" as it reduced the subacromial space and therefore made it easier for the rotator cuff to get in contact with the acromion. He consequently described a technique to excise the "spur" in order to treat the symptoms coming from the contact between the acromion and the humeral head. This procedure was called "acromioplasty". ${ }^{8}$ Neer was also one of the first to classify the impingement lesions and described three stages depending on the amount of damage in the subacromial space and the age of the patient (Table 1).

Different hypotheses were considered to describe the pathogenesis of the SAIS; however, a clear explanation has not been found yet.

First of all, it is not clear yet if the damage to the rotator cuff tendons leads to the impingement (intrinsic mechanism) or if the impingement causes the damage to the tendons (extrinsic mechanism). ${ }^{9,10}$ The theories supporting the intrinsic mechanism are becoming more and more popular in the last few years. ${ }^{11,12}$ These theories argue that the poor vascularity of the supraspinatus tendon (SSP) insertion could

Table I Neer's classification: stages of subacromial impingement Stage I: Edema and hemorrhage, age $<25$ years, reversible

Stage 2: Fibrosis and tendinitis, age $25-40$ years, recurrent pain with activity

Stage 3: Bone spurs and tendon rupture, age $>40$ years, progressive disability be a significant factor in the pathogenesis of degenerative rotator cuff tears. ${ }^{10,12}$ The SSP mainly derives its blood supply from the anterior circumflex humeral and suprascapular arteries; near its insertion at the greater tuberosity, there is an avascular area, also called "critical" zone, which is usually where the tear originates. ${ }^{10}$ The insertional damage to the tendon fibers usually increases in size with the patient's age, and it is more common in diabetic patients and patients with rheumatoid arthritis. ${ }^{13}$ Histological findings are more typical of a "failed healing response", with a haphazard proliferation of tenocytes, intracellular abnormalities in tenocytes, disruption of collagen fibers, and subsequent increase in noncollagenous matrix. ${ }^{11,14}$

For 40 years, the supporters of the extrinsic theory tried to correlate shoulder pain to shoulder "impingement". The shape of the acromion was examined and classified into flat (type I), curved (type II), or hooked (type III) and considered cause of "impingement" as result of the reduced distance in the subacromial space. ${ }^{15,16}$ The shape is age related or congenital is not clear. ${ }^{17}$ Also the anatomy of the thoracic spine was taken into consideration as it was seen to be linked to different possible orientations of the scapula. In patients with "impingement", the scapula can be found to be more protracted and the thoracic spine ${ }^{18}$ more flexed. Today, extrinsic factors also include those which have a biological implication on the subacromial space such as heavy physical loading, injury, vibration, infection, smoking, genetic factors, and fluoroquinolone antibiotics ${ }^{19}$ which ultimately lead to rotator cuff diseases and shoulder pain. Dynamic, musclerelated theories were also described: weakness in the rotator cuff alters the glenohumeral and scapulothoracic kinematics with consequent superior migration of the humeral head and loss of the compression forces that regulate the glenohumeral movements. Similarly, periscapular muscle weakness lead to a late activation of the lower trapezius and the serratus anterior and an early recruitment of the upper trapezius fibers ${ }^{20}$ reducing the ability to externally rotate, tilt posteriorly, and rotate the scapula upward, so that it is more difficult to clear the humeral head during the movements of abduction and external rotation. ${ }^{21}$

Today, the uncertainty regarding the pathogenesis of SAIS is reflected by the confusion regarding its treatment. Since Neer's “impingement" description in $1972,{ }^{8}$ acromioplasty with bursectomy has been the gold standard for patients unresponsive to conservative treatments. In the last years, authors challenged the need for surgery in SAIS. A more comprehensive understanding of the pathogenesis lead to the publication of several papers which questioned the benefit 
of decompression surgery and the rationale of the "impingement" mechanism stating that placebo effect, prolonged rest, and intense physiotherapy after surgery have to be considered the true treatments. ${ }^{22-27}$

Conservative treatment yields satisfactory results within 2 years in $60 \%$ of cases. Studies showed that conservative management of shoulder impingement syndrome resolves the problem in $70 \%-90 \%$ of patients. ${ }^{28}$ In the absence of major structural damage, conservative multimodal treatment for 3-6 months is the initial therapy of choice. Conservative management includes exercise therapy, ultrasound treatment, and subacromial injections (Table 2).

Today, acromioplasty has left space to arthroscopic subacromial decompression (ASD) procedure, which is the gold standard to surgically treat SAIS. The procedure includes debridement of the subacromial bursa, resection of the coracoacromial ligament, and the anterolateral edge of the acromion, as well as any underhanging osteophytes from the acromioclavicular joint. ${ }^{29}$ In the last 25 years, ASD was often adopted because of lower morbidity: including risks of infection and neurovascular damage.

This review of the literature describes the historically accepted methods of treatment of SAIS and wants to discuss if acromioplasty (open or arthroscopic) is to be considered as an out-of-date procedure today and hence is not necessary in patients who have failed to improve with conservative management. The aim of the study was to analyze and describe the current concepts linked to SAIS and shoulder pain and clarify the role of subacromial decompression in the treatment of SAIS.

\section{Literature search and study selection}

A search of the literature in PubMed, PEDro, Embase, and the Cochrane Central Register of Controlled Trials was conducted to identify relevant publications from Neer's paper in 1972 until 2018. Key words such as shoulder impingement syndrome, subacromial space, subacromial decompression,

Table 2 Conservative treatment options

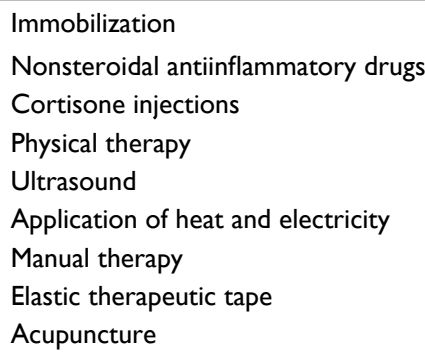

rotator cuff impingement, rotator cuff tears, tendinopathy, and tendinitis were used for the literature search.

All the articles were in English, except one published in German. Reference lists of retrieved articles and articles on surgical interventions for SAIS were screened for additional publications. Names of first authors of selected articles were used for citation tracking.

The articles were independently reviewed by two authors (PC and GS) and the inclusion criteria analyzed from the titles and abstracts of the references retrieved by the literature search. A third reviewer $(\mathrm{OH})$ was consulted if disagreement regarding the inclusion criteria was met. RCTs comparing surgical treatment and conservative treatment for the management of SAIS were included. Prospective articles studying outcome of surgical decompression and physical therapy were also included. Studies focusing on surgical repair of rotator cuff tears, adhesive capsulitis, and shoulder instability were excluded. All the studies included reported outcomes in adult patients ( $>18$ years) only. In all the studies, patients underwent surgery only if failed to improve with conservative treatments for 3-6 months. Mixtures of outcome measures were used in the studies selected. However, the Constant Score appeared to be the most frequently used even if not always as primary outcome measurement. A quantitative analysis (meta-analysis) was not possible because of the diversity in outcome measures used in the various studies (Figure 1). A qualitative analysis was hence performed. The minimum follow-up was 6 months $^{27}$ and the longest was 13 years. ${ }^{22}$ Studies with large group of patients enrolled and long-term follow-up were preferred. Inclusion and exclusion criteria are reported in Table 3. Each article was graded (unclear, low, or high risk of bias) based on sequence generation, allocation concealment, blinding of participants and personnel, blinding of outcome assessment, incomplete outcome data, other possible bias, intention-to-treat analysis, selective reporting, and baseline characteristics. The risk of bias assessment was completed by one author (PC) and checked by a second author (GS). Disagreements were resolved by discussion, and a third author $(\mathrm{OH})$ was consulted if consensus could not be reached. A Physiotherapy Evidence Database (PEDro) scale was used for rating the seven selected RCT papers.

\section{Results}

The results from seven RCTs, mainly comparing conservative treatment and surgical treatment, were collected and analyzed. Discrepancy in the results was observed (Table 4). The results of an RCT comparing ASD and bursectomy alone were analyzed as it was considered to add value to 


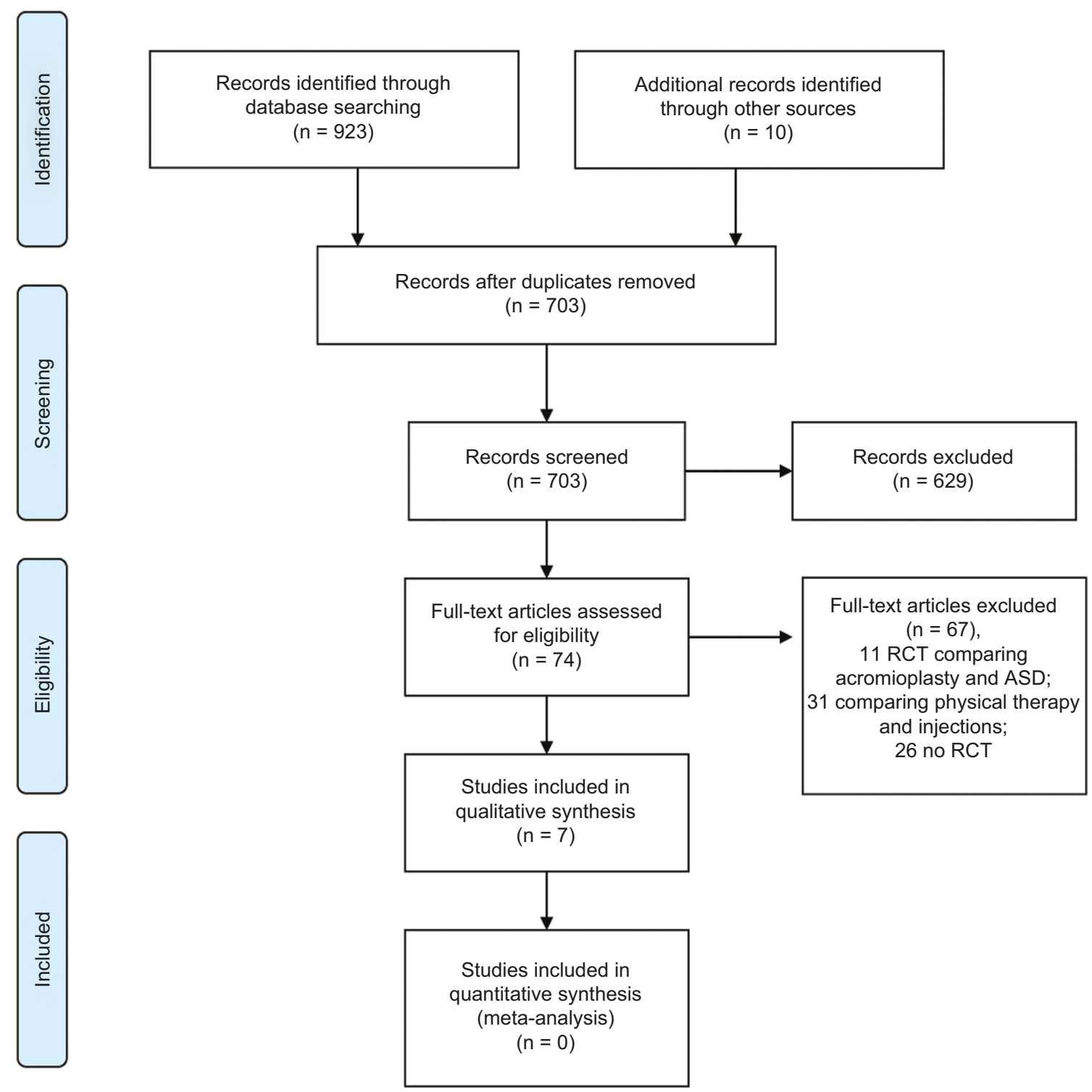

Figure I Flowchart of search strategy.

Source: From Moher D, Liberati A, Tetzlaff J, Altman DG, The PRISMA Group. Preferred Reporting Items for Systematic Reviews and Meta-Analyses: The PRISMA Statement. PLoS Med 2009;6(7):el000097; doi:I0.137I/journal.pmed I000097. For more information, visit www.prisma-statement.org. ${ }^{45}$

Abbreviations: ASD, arthroscopic subacromial decompression; RCT, randomized clinical trial.

the discussion. Of the seven RCTs, three studies were rated high quality, two fair, and two poor using the PEDro scale.

Brox et $\mathrm{al}^{30}$ randomized 125 patients to ASD, physiotherapy, and laser therapy (placebo group). No differences were found between the three groups in duration of sick leave to 6 months (median 3 months) and daily intake of analgesics. Participants in both groups that received active treatment improved significantly more than those in the placebo group at 6 months: median differences between exercises (13.0 [95\% CI 7 to 20]) and surgery (19.5 [95\% CI 12 to 27]) compared with placebo (mean change in Neer score -0.3 with placebo compared with 10.8 in the exercise group and 20.2 in the surgery group). Treatment costs were higher for those given surgery ( 720 pounds) vs those given supervised exercises (390 pounds). This was predominantly due to hospitalization in the surgical group. 
Table 3 Inclusion and exclusion criteria

\begin{tabular}{|l|l|}
\hline Inclusion criteria & Exclusion criteria \\
\hline $\begin{array}{l}\text { Randomized control trials comparing surgical treatment (either open or } \\
\text { arthroscopic) and conservative treatment or no treatment for SAIS }\end{array}$ & $\begin{array}{l}\text { Randomized control trials comparing open and arthroscopic } \\
\text { acromioplasty }\end{array}$ \\
\hline Prospective studies analyzing outcome of ASD for the treatment of SAIS & $\begin{array}{l}\text { Studies including patients with rotator cuff tears who underwent } \\
\text { ASD only }\end{array}$ \\
\hline $\begin{array}{l}\text { Prospective studies analyzing outcome of conservative treatment } \\
\text { (physical therapy) for the treatment of SAIS }\end{array}$ & $\begin{array}{l}\text { Studies including patients with rotator cuff tears who underwent } \\
\text { rotator cuff repair only }\end{array}$ \\
\hline Adult patients (>18 years of age) & $\begin{array}{l}\text { Studies including patients with rotator cuff tears who underwent } \\
\text { rotator cuff repair and ASD }\end{array}$ \\
\hline $\begin{array}{l}\text { Conservative treatment for a minimum of 3-6 months before surgical } \\
\text { intervention was considered }\end{array}$ & Studies including patients with adhesive capsulitis \\
\hline Minimum follow-up of 6 months & Studies including patients with instability \\
\hline Studies comparing ASD and bursectomy alone & Studies including children (<18 years of age) \\
\hline & Studies with minimum follow-up less than 6 months \\
\hline & Young patients (<18 years of age) \\
\hline
\end{tabular}

Abbreviations: SAIS, Subacromial Impingement Syndrome; ASD, arthroscopic subacromial decompression.

Peters and $\mathrm{Kohn}^{31}$ compared either arthroscopic or open acromioplasty to physiotherapy in 72 patients. Surgical patients improved from 54 at baseline to 84 on the Subjective Shoulder Rating Scale; similarly, with no significant difference, patients treated conservatively improved from 59 to 74 .

Rahme et $\mathrm{a}^{32}$ presented the results of 42 patients. At 6 months, treatment in the surgical group had been successful in $12 / 21(57 \%)$ patients vs $6 / 18(33 \%)$ in the physiotherapy group. Before the 12 months follow-up, 13 patients decided to have surgery, therefore, a direct comparison of the two groups at 12 months was not possible.

In 2004, Haahr et a ${ }^{33}$ randomized 90 patients either to ASD or to physiotherapy with exercises aiming at strengthening the stabilizers and decompressors of the shoulder. Of the 90 patients enrolled, 84 completed follow-up (41 in the surgery group, 43 in the training group). The mean CS at baseline was 34.8 in the training group and 33.7 in the surgery group. After 12 months, the mean scores improved to 57.0 and 52.7, respectively, the difference being nonsignificant. No difference in mean pain and dysfunction score improvement was found.

In 2017, a group of researchers from Oxford published a multicenter, randomized, pragmatic, parallel-group trial with 313 patients treated by 51 surgeons in 32 hospitals in the United Kingdom between 2012 and 2015. ${ }^{27}$ They randomized the participants to ASD, arthroscopy only (with no soft tissue or bone removal), and no treatment. Mean Oxford Shoulder Score did not differ between the two surgical groups at 6 months (decompression 32.7 points [SD 11.6] vs arthroscopy 34.2 points [9.2]; mean difference -1.3 points $(95 \%$ CI -3.9 to $1.3, P=0.3141$ ). Both surgical groups showed a small benefit over no treatment (mean 29.4 points [SD 11.9], decompression was higher by 2.8 points [ $95 \%$ CI 0.5 to 5.2 ], $P=0.0186$; mean difference vs arthroscopy by 4.2 points $[1.8$ to 6.6], $P=0.0014$ ), but these differences were not clinically important. Another study by Ketola et $\mathrm{a}^{22}$ reported the longterm results (11-13 years) of arthroscopic acromioplasty in the treatment of rotator cuff tendinopathy observed in 140 patients. The participants were randomized to ASD and supervised exercises and supervised exercises only. At 2 years, 5 years (results previously published ${ }^{23,24}$ ), and over 10 years $^{22}$ follow-up, self-reported pain and visual analog scale (VAS), disability, working ability, pain at night (VAS), and Shoulder Disability Questionnaire score improved in both groups compared with the baseline but no difference was found between the two groups.

Farfaras et $\mathrm{al}^{34}$ published the results of an RCT comparing open acromioplasty, ASD, and physical therapy in SAIS at 10 years follow-up. The strength in both surgical treatment groups improved over time, but the improvement was statistically significant only in the open acromioplasty group $(P=0.003)$. No statistically significant difference over time was seen in the conservative group. CS improved significantly in both surgical groups (open acromioplasty, $P=0.003$; ASD, $P=0.011)$ while, instead, it did not in the group that was treated with physiotherapy only. The Watson and Sonnabend score did not show significant difference among the groups $(P=0.14)$. Ultrasound and XRs were used at the follow-up to detect possible rotator cuff tears, superior migration of the humeral head, bursitis, and gleno humeral osteoarthritis; no differences were found in the three groups. 


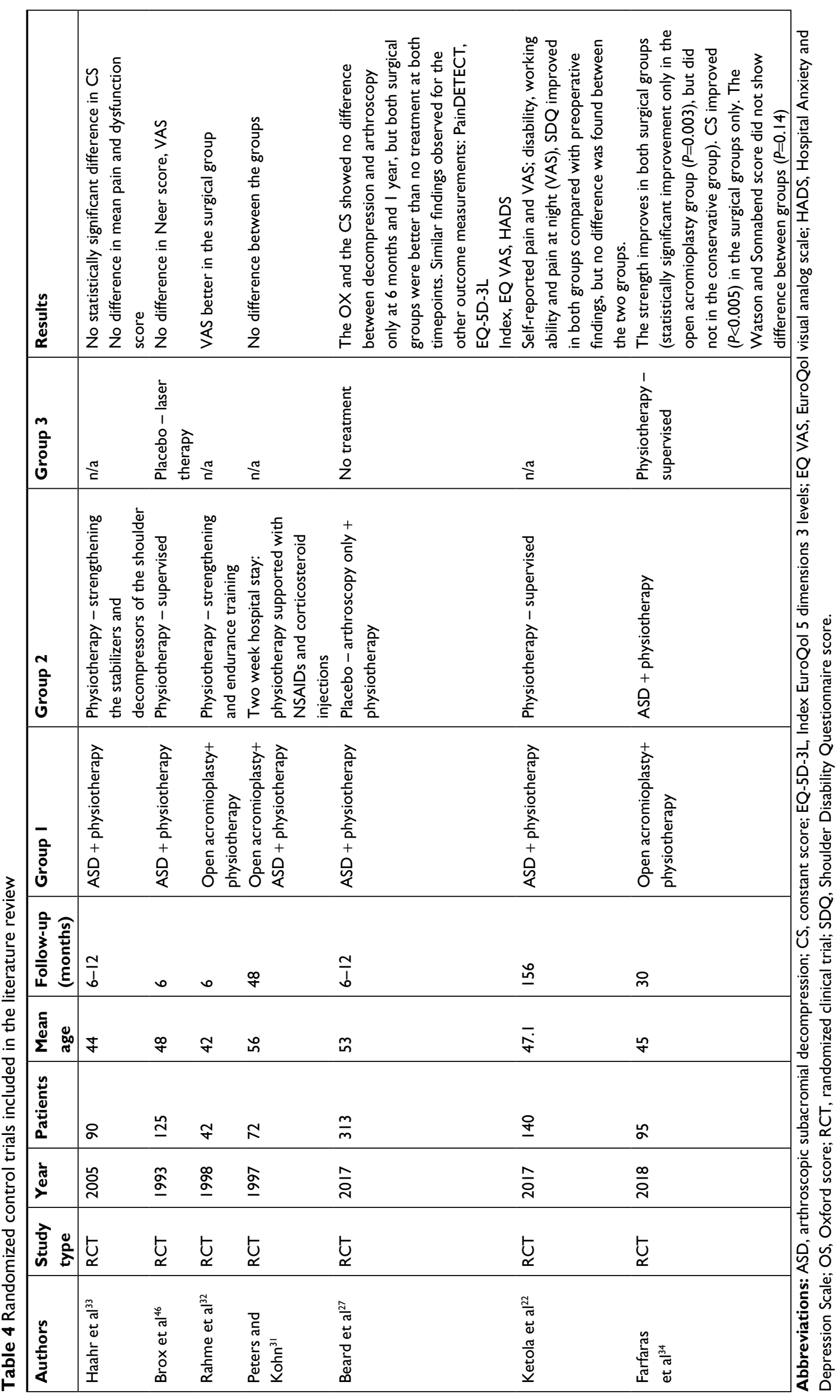




\section{Discussion}

For the past 50 years, since Charles Neer introduced the acromioplasty technique, surgical intervention has been often considered in those patients who failed with conservative treatment.

In the last years, concerns raised regarding the benefit of performing surgery in SAIS. New considerations regarding the pathogenesis ${ }^{11}$ of the disease have challenged the technique proposed by Neer in $1972 .{ }^{8}$ Authors have proposed that postoperative rest and physiotherapy might be the real cures for SAIS; different studies have concluded that surgery could only have a placebo effect and might be not necessary.

The results of RCT studies published in the last 15-20 years reflect the progress made in understanding the pathogenesis of shoulder pain; the "impingement" concept, as Neer described it, looks antiquate today. ${ }^{11}$ Better understanding of the intrinsic mechanisms as causes of the pain and disability experienced by the patients have emphasized the importance of rotator cuff tendons state in the natural history of the subacromial pain. For this reason, it has been proposed to change the name to "anterolateral" shoulder pain syndrome instead of "impingement" syndrome, which emphasized more on the mechanical aspect of the problem. ${ }^{11}$ Hence, shoulder pain is not necessarily caused by the contact between the acromion and the cuff, but originates from the rotator cuff tendons ${ }^{12}$ and is mediated by the free nerve endings in the bursa. ${ }^{35}$

This new concept is supported by a number of RCTs (Peters and Kohn, ${ }^{31}$ Haahr et al, ${ }^{33}$ Ketola et a ${ }^{22-24}$ ) that haven't observed the supremacy of surgery on conservative treatment. Physiotherapy was seen to provide good outcome, comparable to those achieved with surgery but without the costs and the complications that are intrinsically connected to surgery. More recently, in 2017, Beard et al ${ }^{27}$ showed that the outcome achieved by the surgical groups are statistically significantly better than those reached by the no treatment group, however, the differences have uncertain clinical mean. ${ }^{27}$ The difference was more significant at 6 months compared with 12 months follow-up as most of the patients in the no treatment group felt much improved and satisfied with the results after 1 year. Interestingly, one of the two surgical groups had only a diagnostic arthroscopy and no removal of soft tissue or bone from the subacromial space was undertaken (placebo group). Following these findings, they suggested that the results of the ASD group could be related to the prolonged rest and postoperative physiotherapy and not to the procedure itself. Despite the study having some limitations, such as the level of noncompliance to treatment allocation and the short follow-up, it strongly disputes the need for surgery for
SAIS. To reinforce these findings, Henkus et $\mathrm{al}^{26}$ reported the results of an RCT with 57 patients and 2.5 years mean follow-up where the results of arthroscopic bursectomy only and ASD were compared. No differences were found in the two groups. This study stressed the strength of placebo effect related to surgery and challenged the need for removal of bone from the acromion as might not be necessary. As the RCT published by Beard et $\mathrm{al}^{27}$ has got very limited follow-up and therefore the results need to be analyzed very carefully, Ketola et $\mathrm{al}^{22}$ described long-term results (11-13 years) of an RCT assessing the benefit of arthroscopic acromioplasty and supervised exercises compared to supervised exercises only, in the treatment of rotator cuff tendinopathy. At 10 years ${ }^{22}$ follow-up, no differences were seen in the outcome of the two groups despite a significant improvement was seen in the outcome compared with the baseline.

However, despite the number of RCTs challenging the need for surgery in SAIS, it is necessary to critically analyze the data and avoid confusion. The surgical findings observed in the subacromial space ${ }^{36}$ during shoulder arthroscopy are hard to be explained if not for a contact between the rotator cuff and the acromion. The classification described by Atoun et $\mathrm{al}^{36}$ (Copeland-Levy classification) applies to different degrees of damage observed on the undersurface of the acromion and the bursal side of the rotator cuff. These findings are secondary to an "impingement", considered as a mechanical contact between the humeral head and acromion, ${ }^{37}$ but can be primarily related to an intrinsic impairment of the rotator cuff (mainly the SSP tendon insertion) with loss of shoulder depression function. ${ }^{38}$

None of the reviewed studies consider the degree of subacromial damage occurred to the rotator cuff and the acromion and coracoacromial ligament. Intrinsic tendon damage and consequent rotator cuff failure were already described by Neer et al as "fibrillation". Arthroscopy helped to classify the different lesions and their severity ${ }^{36}$ and confirmed that, despite the pathogenesis, a contact between the cuff and the acromion occurs in certain patients with SAIS. Under this circumstance, we believe that surgical decompression can still be considered the appropriate treatment. ${ }^{29,34,39-41}$

An RCT published by Farfaras et $\mathrm{al}^{34}$ reported the good results of ASD at 10-year follow-up. They found that the groups randomized to surgery (open or arthroscopic decompression) maintained better long-term results (CS) compared with the patients randomized to physical therapy. These outcomes are in line with other study results which, however, are not coming from randomized trial and have shorter follow-up. ${ }^{40,42}$ Considering the long-term effect of 
surgical decompression, also for patients $>60$ years of age,$^{34}$ authors considered the possibility of long-term protective effect of subacromial decompression in SAIS patients. ${ }^{40,43}$ Even if there were no statistically significant differences, Farfaras et $\mathrm{al}^{34}$ reported a higher incidence of rotator cuff tears at the follow-up (ultrasound) in the group treated with physical therapy compared with the surgical groups (open acromioplasty: 1; ASD: 1; physiotherapy: 4).

Further studies are necessary to separately analyze in different groups, patients with signs of intrinsic failure of the rotator cuff and involvement of the acromial arch, considered as structural changes in the subacromial space, from patients with no abnormality. Patients with a more advanced stage of the disease might benefit from surgical decompression more than those in whom marked changes in the subacromial space have not occurred yet.

This might explain well why some patients often struggle to regain good shoulder function with conservative treatment only and hence they are often referred to secondary care centers to consider surgical intervention.

\section{Conclusion}

SAIS is considered to be one of the most common forms of shoulder pathology in the general population ${ }^{3}$ disabling numerous patients. The pathogenesis is not fully understood, but recent studies moved the attention from the extrinsic mechanism of "impingement" to intrinsic causes related to poor microvascularity of the insertion of the SSP tendon. ${ }^{11,13,14}$ The source of pain is mediated by the free nerve endings which are in the bursa and is thought to be related to the degree of damage to the SSP tendon. ${ }^{35}$

Hence, as the "spur" described by Neer ${ }^{8}$ is not considered the source of the pain anymore, acromioplasty was challenged. ${ }^{22,27}$ Several RCTs $\mathrm{R}^{22,25,27,33,44}$ reported that acromioplasty does not add any benefit to conservative treatments. Placebo effect of surgery and the effectiveness of prolonged rest and physiotherapy were considered as the real cures for the symptoms.

However, the conclusion is not that simple as other studies reported good outcome after ASD and better long-term results when compared with patients treated with conservative treatments only. ${ }^{29,34,39-41}$ Many RCTs which encourage the use of exercises and physiotherapy, as these seem to give similar results to surgery, do not offer solution to those patients who fail in conservative management. Classification of the subacromial lesions needs to be considered to fully understand the response of SAIS patients to different treatments. Surgical decompression still needs to be considered when conservative treatment fails. In this specific group of patients, we believe the outcome of surgery can be compared with the intraoperative classification of the impingement lesion. Further RCTs with stricter clinical and imaging criteria must be developed to further understand the response of patients with SAIS to conservative treatment and surgery. A better understanding of the anatomo-pathology is mandatory to improve our indications to treatment.

\section{Disclosure}

The authors report no conflicts of interest in this work.

\section{References}

1. Bhattacharyya R, Edwards K, Wallace AW. Does arthroscopic sub-acromial decompression really work for sub-acromial impingement syndrome: a cohort study. BMC Musculoskelet Disord. 2014; $15: 324$.

2. van der Windt DA, Koes BW, de Jong BA, Bouter LM. Shoulder disorders in general practice: incidence, patient characteristics, and management. Ann Rheum Dis. 1995;54(12):959-964.

3. Linsell L, Dawson J, Zondervan K, et al. Prevalence and incidence of adults consulting for shoulder conditions in UK primary care; patterns of diagnosis and referral. Rheumatology (Oxford). 2006;45(2):215-221.

4. Bodin J, Ha C, Petit Le Manac'h A, et al. Risk factors for incidence of rotator cuff syndrome in a large working population. Scand J Work Environ Health. 2012;38(5):436-446.

5. Michener LA, Walsworth MK, Doukas WC, Murphy KP. Reliability and diagnostic accuracy of 5 physical examination tests and combination of tests for subacromial impingement. Arch Phys Med Rehabil. 2009;90(11):1898-1903.

6. Pesquer L, Borghol S, Meyer P, Ropars M, Dallaudière B, Abadie P. Multimodality imaging of subacromial impingement syndrome. Skeletal Radiol. 2018;47(7):923-937.

7. Graichen H, Bonel H, Stammberger T, Englmeier KH, Reiser M, Eckstein F. Subacromial space width changes during abduction and rotation--a 3-D MR imaging study. Surg Radiol Anat. 1999;21(1):59-64.

8. Neer CS 2nd. Anterior acromioplasty for the chronic impingement syndrome in the shoulder: a preliminary report. J Bone Joint Surg Am. 1972;54(1):41-50.

9. Uhthoff HK, Sarkar K. Classification and definition of tendinopathies. Clin Sports Med. 1991;10(4):707-720.

10. Lohr JF, Uhthoff HK. The microvascular pattern of the supraspinatus tendon. Clin Orthop Relat Res. 1990;(254):35-38.

11. McFarland EG, Maffulli N, Del Buono A, Murrell GA, GarzonMuvdi J, Petersen SA. Impingement is not impingement: the case for calling it "Rotator Cuff Disease". Muscles Ligaments Tendons J. 2013;3(3):196-200.

12. Ozaki J, Fujimoto S, Nakagawa Y, Masuhara K, Tamai S. Tears of the rotator cuff of the shoulder associated with pathological changes in the acromion. A study in cadavera. J Bone Joint Surg Am. 1988;70(8):1224-1230.

13. Ling SC, Chen CF, Wan RX. A study on the vascular supply of the supraspinatus tendon. Surg Radiol Anat. 1990;12(3):161-165.

14. Del Buono A, Battery L, Denaro V, Maccauro G, Maffulli N. Tendinopathy and inflammation: some truths. Int J Immunopathol Pharmacol. 2011;24(1 Suppl 2):45-50.

15. Bigliani LU, Levine WN. Subacromial impingement syndrome. J Bone Joint Surg Am. 1997;79(12):1854-1868.

16. Weiner DS, Macnab I. Superior migration of the humeral head. A radiological aid in the diagnosis of tears of the rotator cuff. J Bone Joint Surg Br. 1970;52(3):524-527. 
17. Seitz AL, McClure PW, Finucane S, Boardman ND 3rd, Michener LA. Mechanisms of rotator cuff tendinopathy: intrinsic, extrinsic, or both? Clin Biomech (Bristol, Avon). 2011;26(1):1-12.

18. Lewis JS, Wright C, Green A. Subacromial impingement syndrome: the effect of changing posture on shoulder range of movement. J Orthop Sports Phys Ther. 2005;35(2):72-87.

19. Danielson P, Andersson G, Alfredson H, Forsgren S. Marked sympathetic component in the perivascular innervation of the dorsal paratendinous tissue of the patellar tendon in arthroscopically treated tendinosis patients. Knee Surg Sports Traumatol Arthrosc. 2008;16(6):621-626.

20. Ludewig PM, Braman JP. Shoulder impingement: biomechanical considerations in rehabilitation. Man Ther. 2011;16(1):33-39.

21. Diederichsen LP, Nørregaard J, Dyhre-Poulsen P, et al. The activity pattern of shoulder muscles in subjects with and without subacromial impingement. J Electromyogr Kinesiol. 2009;19(5):789-799.

22. Ketola S, Lehtinen JT, Arnala I. Arthroscopic decompression not recommended in the treatment of rotator cuff tendinopathy a final review of a randomised controlled trial at a minimum follow-up of ten years. Bone Joint J. 2017;99-B(6):799-805.

23. Ketola S, Lehtinen J, Arnala I, et al. Does arthroscopic acromioplasty provide any additional value in the treatment of shoulder impingement syndrome?: a two- year randomised controlled trial. J Bone Joint Surg Br. 2009;91(10):1326-1334.

24. Ketola S, Lehtinen J, Rousi T, et al. No evidence of long-term benefits of arthroscopic acromioplasty in the treatment of shoulder impingement syndrome: five-year results of a randomised controlled trial. Bone Joint Res. 2013;2(7):132-139.

25. Dorrestijn O, Stevens M, Winters JC, van der Meer K, Diercks RL. Conservative or surgical treatment for subacromial impingement syndrome? A systematic review. J Shoulder Elbow Surg. 2009;18(4):652-660.

26. Henkus HE, de Witte PB, Nelissen RG, Brand R, van Arkel ER. Bursectomy compared with acromioplasty in the management of subacromial impingement syndrome: a prospective randomised study. J Bone Joint Surg Br. 2009;91(4):504-510.

27. Beard DJ, Rees JL, Cook JA, et al. Arthroscopic subacromial decompression for subacromial shoulder pain (CSAW): a multicentre, pragmatic, parallel group, placebo-controlled, three-group, randomised surgical trial. Lancet. 2018;391(10118):329-338.

28. Garofalo R, Conti M, Massazza G, Cesari E, Vinci E, Castagna A. Subcoracoid impingement syndrome: a painful shoulder condition related to different pathologic factors. Musculoskelet Surg. 2011;95(Suppl 1):S25-S29.

29. Ellman H. Arthroscopic subacromial decompression: analysis of one- to three-year results. Arthroscopy. 1987;3(3):173-181.

30. Brox JI, Gjengedal E, Uppheim G, et al. Arthroscopic surgery versus supervised exercises in patients with rotator cuff disease (stage II impingement syndrome): a prospective, randomized, controlled study in 125 patients with a 2 1/2-year follow-up. J Shoulder Elbow Surg. 1999;8(2):102-111.

31. Peters G, Kohn D. Mid-term clinical results after surgical versus conservative treatment of subacromial impingement syndrome. Unfallchi rurg.1997;100(8):623-629. German.
32. Rahme H, Solem-Bertoft E, Westerberg CE, Lundberg E, Sörensen S, Hilding $\mathrm{S}$. The subacromial impingement syndrome. A study of results of treatment with special emphasis on predictive factors and paingenerating mechanisms. Scand J Rehabil Med. 1998;30(4):253-262.

33. Haahr JP, Østergaard S, Dalsgaard J, et al. Exercises versus arthroscopic decompression in patients with subacromial impingement: a randomised, controlled study in 90 cases with a one year follow up. Ann Rheum Dis. 2005;64(5):760-764.

34. Farfaras S, Sernert N, Rostgard Christensen L, Hallström EK, Kartus JT. Subacromial decompression yields a better clinical outcome than therapy alone: a prospective randomized study of patients with a minimum 10-year follow-up. Am J Sports Med. 2018;46(6):1397-1407.

35. Vangsness CT, Ennis M, Taylor JG, Atkinson R. Neural anatomy of the glenohumeral ligaments, labrum, and subacromial bursa. Arthroscopy.1995;11(2):180-184.

36. Atoun E, Gilat R, van Tongel A, et al. Intraobserver and interobserver reliability of the Copeland-Levy classification for arthroscopic evaluation of subacromial impingement. J Shoulder Elbow Surg. 2017;26(12):2167-2172.

37. Flatow EL, Soslowsky LJ, Ticker JB, et al. Excursion of the rotator cuff under the acromion. Patterns of subacromial contact. Am J Sports Med. 1994;22(6):779-788.

38. Neviaser A, Andarawis-Puri N, Flatow E. Basic mechanisms of tendon fatigue damage. J Shoulder Elbow Surg. 2012;21(2):158-163.

39. Klintberg IH, Svantesson U, Karlsson J. Long-term patient satisfaction and functional outcome 8-11 years after subacromial decompression. Knee Surg Sports Traumatol Arthrosc. 2010;18(3):394-403.

40. Lunsjö K, Bengtsson M, Nordqvist A, Abu-Zidan FM. Patients with shoulder impingement remain satisfied 6 years after arthroscopic subacromial decompression: a prospective study of 46 patients. Acta Orthop. 2011;82(6):711-713.

41. Björnsson H, Norlin R, Knutsson A, Adolfsson L. Fewer rotator cuff tears fifteen years after arthroscopic subacromial decompression. J Shoulder Elbow Surg. 2010;19(1):111-115.

42. Roddy E, Zwierska I, Hay EM, et al. Subacromial impingement syndrome and pain: protocol for a randomised controlled trial of exercise and corticosteroid injection (the SUPPORT trial). BMC Musculoskelet Disord. 2014;15:81.

43. Biberthaler P, Beirer M, Kirchhoff S, Braunstein V, Wiedemann E, Kirchhoff C. Significant benefit for older patients after arthroscopic subacromial decompression: a long-term follow-up study. Int Orthop. 2013;37(3):457-462.

44. Ng C, Bialocerkowski A, Hinman R. Effectiveness of arthroscopic versus open surgical stabilisation for the management of traumatic anterior glenohumeral instability. Int J Evid Based Healthc. 2007;5(2):182-207.

45. Moher D, Liberati A, Tetzlaff J, Altman DG, The PRISMA Group Preferred Reporting Items for Systematic Reviews and Meta-Analyses: The PRISMA Statement. PLoS Med 2009;6(7):e1000097.

46. Brox JI, Staff PH, Ljunggren AE, Brevik JI. Arthroscopic surgery compared with supervised exercises in patients with rotator cuff disease (stage II impingement syndrome). BMJ. 1993;307(6909):899-903.
Orthopedic Research and Reviews

\section{Publish your work in this journal}

Orthopedic Research and Reviews is an international, peer-reviewed, open access journal that focusing on the patho-physiology of the musculoskeletal system, trauma, surgery and other corrective interventions to restore mobility and function. Advances in new technologies, materials, techniques and pharmacological agents are particularly welcome. The manuscript management system is completely online and includes a very quick and fair peer-review system, which is all easy to use. Visit http://www.dovepress.com/testimonials.php to read real quotes from published authors. 